\title{
Breaking and entering
}

DOI:

10.1038/nrc2077

\section{URLs}

$\mathrm{NF} \kappa \mathrm{B}$

http://www.ncbi.nlm.nih.gov/ entrez/query.fcgi?db=gene\&c $\mathrm{md}=$ Retrieve\&dopt=full report\&list_uids $=4790$

\section{GMCSF}

http://www.ncbi.nlm.nih.gov/ entrez/query.fcgi?db=gene\&c $\mathrm{md}=$ Retrieve\&dopt=full reportElist_uids=1437
Breast cancer cells frequently spread to bone, making bone metastases a significant clinical problem in patients with advanced disease. Bae Park and Cun-Yu Wang have now shown that the transcriptional regulator nuclear factor $\kappa \mathrm{B}(\mathrm{NF} \kappa \mathrm{B})$ is important in establishing osteolytic bone metastasis.

Given the well-established role of NFKB in metastasis, the authors assessed its involvement in breast cancer metastasis to bone. They retrovirally transduced the breast cancer cell line MDA-MB-231 with a non-degradable form of the NFKBspecific inhibitor $\mathrm{I} \kappa \mathrm{B} \alpha$ that functions as an NFKB super-repressor. MDAMB-231 cells are known to preferentially metastasize to bone, but the cells that expressed I $\mathrm{B} \alpha$ (MDA/I cells) were less able to produce bone lesions after injection into mice through the left ventricle of the heart. Microradiograph and histological analyses showed that only four of nine mice developed osteolytic bone lesions, and tumour expansion in the marrow cavity and bone destruction were less extensive compared with metastases established after the injection of MDA-MB-231 cells. In addition, osteoclast-mediated bone destruction is known to be important for the growth of bone metastases, and fewer osteoclasts were evident at the bone-tumour interface in mice injected with MDA/I cells.

The authors examined the expression profile of the MDA/I cells and found that the gene that encodes granulocyte-macrophage colony stimulating factor (GMCSF) was downregulated following NFKB inhibition. The restored expression of GMCSF in MDA/I cells re-established the ability of the cells to form osteolytic bone metastases in vivo, whereas knocking down GMCSF levels, through the use of short hairpin RNA or specific antibodies, significantly reduced the number of metastases, osteoclasts and bone destruction. Accordingly, the authors showed that human breast tumours that have metastasized to bone express GMCSF, and this correlates with the nuclear localization of NFKB.
These findings indicate that NFKB and GMCSF are potential therapeutic targets for the treatment of breast cancer patients with osteolytic bone metastases, and might also prove to be useful targets for the prevention of bone metastases.

Francesca Pentimalli

ORIGINAL RESEARCH PAPER Park, B. K. \& Wang C. Y. NF- $\mathrm{KB}$ in breast cancer cells promotes osteolytic bone metastasis by inducing osteoclastogenesis via GM-CSF. Nature Med. 10 Dec 2006 (doi: 10.1038/nm1519)

FURTHER READING Mundy, G. R. Metastasis to bone: causes, consequences and therapeutic opportunities. Nature Rev. Cancer 2, 584-593 (2002)

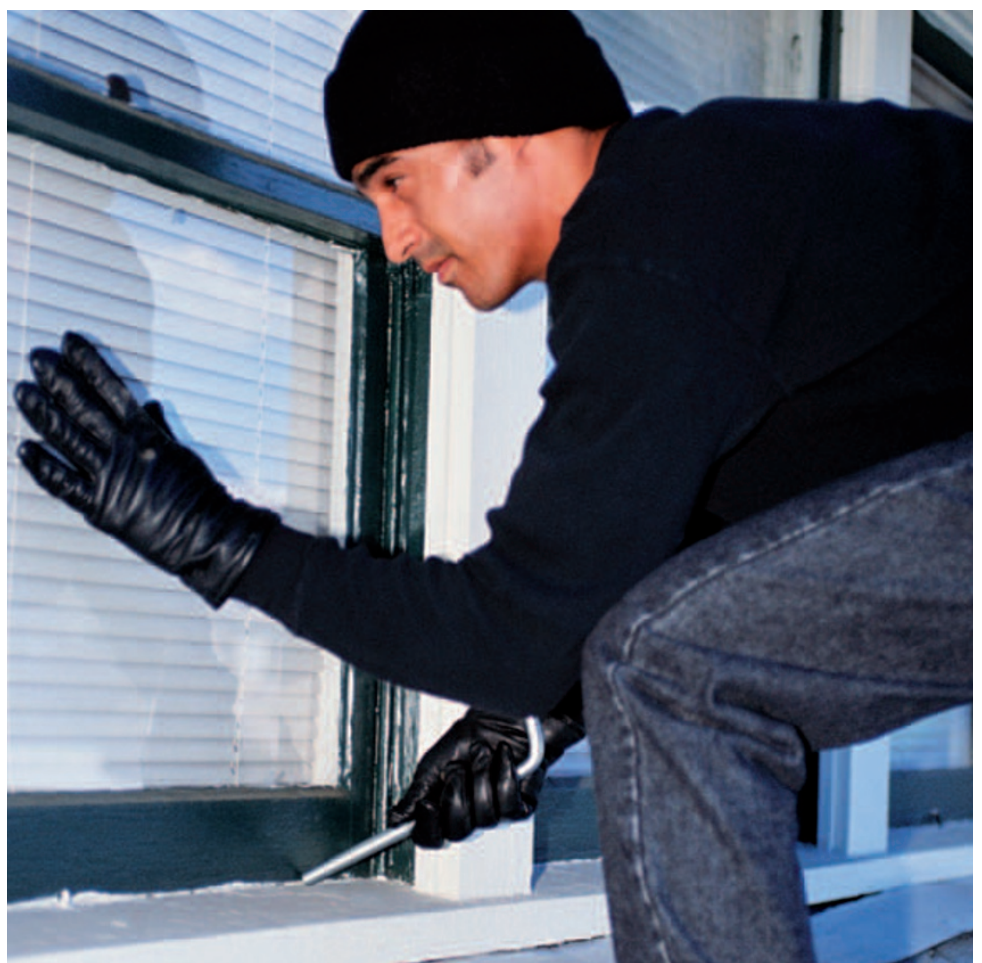

